\title{
Multilocus Phylogenetic Diversity of Fusarium avenaceum Pathogenic on Lisianthus
}

\author{
F. A. Nalim, W. H. Elmer, R. J. McGovern, and D. M. Geiser
}

First and fourth authors: Department of Plant Pathology, Pennsylvania State University, University Park 16802; second author: Department of Plant Pathology and Ecology, The Connecticut Agricultural Experiment Station, P.O. Box 1106, New Haven 06504; and third author: Department of Plant Pathology, IFAS, University of Florida, P.O. Box 110680, Gainesville 32611.

Current address of first author: New Mexico State University, Las Cruces 88003.

Accepted for publication 1 December 2008.

\begin{abstract}
Nalim, F. A., Elmer, W. H., McGovern, R. J., and Geiser, D. M. 2009. Multilocus phylogenetic diversity of Fusarium avenaceum pathogenic on lisianthus. Phytopathology 99:462-468.

Fusarium avenaceum is a globally distributed fungus commonly isolated from soil and a wide range of plants. Severe outbreaks of crown and stem rot of the flowering ornamental, lisianthus (Eustoma grandiflorum), have been attributed to $F$. avenaceum. We sequenced portions of the translation elongation factor 1-alpha (tef) and beta-tubulin (ben A) protein

lates were an exclusive group with strong bootstrap support and no significant incongruence among gene genealogies. Isolates from lisianthus were scattered within this clade and did not form distinct groups based on host species or locality. Pathogenicity tests of $F$. avenaceum isolates obtained from several other hosts showed an ability to cause disease on lisianthus, suggesting that $F$. avenaceum may be pathogenic on lisianthus regardless of its phylogenetic origin. These findings have management implications and suggest that any host that supports $F$. avenaceum may serve as a source of inoculum for lisianthus growers.
\end{abstract} coding genes as well as partial intergenic spacer (IGS) regions of the nuclear ribosomal genes in 37 Fusarium isolates obtained from lisianthus and other host plants. Isolates that were previously identified morphologically as $F$. acuminatum were included as an outgroup. Phylogenetic analyses of tef, benA, and IGS sequences showed that $F$. avenaceum iso-
Additional keywords: evolution, Fusarium arthrosporioides, genealogical concordance, Gibberella acuminata, host specificity, morphospecies, taxonomy.
Fusarium is a large, ubiquitous genus of ascomycetous fungi that includes many important plant pathogens and mycotoxin producers as well as saprophytes and endophytes. Correct species identification is very important for determining the ecological roles of Fusarium species and for diagnosing disease. The morphology of microscopic characteristics, particularly the shape and dimensions of macroconidia, has been the primary classical means of identifying and defining Fusarium species. Morphology-based taxonomic systems have recognized as many as 78 Fusarium species (11), and as few as nine (33-35), but molecular phylogenetic approaches using genealogical concordance phylogenetic species recognition (GCPSR) (37) identify far more $(1,10$, 17,23,26,28,29). For example, Fusarium oxysporum, a ubiquitous soil species, is successful both as a saprophyte and as a pathogen with a wide host range (12), and many formae speciales of $F$. oxysporum have been recognized within this species based on host specificity. However, molecular phylogenetic analyses of $F$. oxysporum have demonstrated that this morphospecies is actually an extremely diverse complex of lineages that show some continental biogeographic structure (32). Molecular phylogenetic analyses have also demonstrated multiple independent origins of formae speciales in this complex, indicating that this is not a reliable taxonomic category, as common host specificity is often the result of convergent evolution $(2,32)$.

In this study, we explored the relationship between host and evolutionary origin in F. avenaceum (Fr.) Sacc., focusing on crown and stem rot disease of lisianthus. F. avenaceum occurs in

Corresponding author: F. A. Nalim; E-mail address: fanalim@ @msu.edu

doi:10.1094/PHYTO-99-4-0462

(c) 2009 The American Phytopathological Society many states besides Florida, California, and Connecticut and in many countries besides the United States, and can be isolated from many different host species besides lisianthus (4). It is also commonly isolated from soil and can exist as a parasite or as a saprophyte. It is responsible for root and stem rots of cereals, legumes, and vegetables and is often associated ecologically with $F$. culmorum and $F$. graminearum $(5,6)$. Although $F$. avenaceum causes disease on a wide range of hosts, it is not known if host specificity exists among certain strains and lisianthus.

Many potted ornamentals, like lisianthus, have diseases caused by several Fusarium species $(13,31)$. Recent severe outbreaks of crown and stem rot of lisianthus have been attributed to $F$. avenaceum (16). Crown and stem rot of lisianthus became widespread in Florida and California in 1995, with plant mortality as great as $70 \%$ and losses in excess of $\$ 100,000$ at several production facilities in both states. $F$. avenaceum may be spread by air, the reuse of transplant trays infested with $F$. avenaceum, and by fungus gnats (15). In addition to good sanitation practices, fungicides are the main agents used to control $F$. avenaceum. In spite of its importance, very little research has been carried out in recent years to study this disease $(7,15,16)$. Elmer and McGovern (7) first hypothesized that clonal populations were causing the outbreak and spreading on lisianthus seedlings. They found that isolates from one greenhouse were vegetatively compatible with each other, while isolates from different sites and regions were not (7). These findings suggested that clonal spread may occur within a greenhouse, even if the pathogenic population of $F$. avenaceum represented many vegetatively incompatible isolates.

The cosmopolitan nature of $F$. avenaceum, and its diverse host range, suggests that this morphospecies may comprise multiple phylogenetic species. F. avenaceum is characterized by long, slender, straight to falcate macroconidia, produced in large, 
orange-colored sporodochia, as well as mesoconidia produced from polyphialides. It is morphologically distinctive, although it has some similarities with other species. F. arthrosporioides Sherb., for example, is morphologically similar to F. avenaceum, but produces greater numbers of microconidia and generally does not produce large, orange sporodochia (11).

Using three gene regions, and based on GCPSR, we sought to identify Fusarium species that cause crown and stem rot of lisianthus. We sequenced portions of two protein-coding genes, translation elongation factor 1-alpha (tef) and beta-tubulin (ben $\mathrm{A})$, and the intergenic spacer (IGS) regions of the nuclear ribosomal RNA gene repeat and carried out a phylogenetic analysis. Previous work using these genes has shown that they are variable between closely related species even when no morphological differences are apparent $(9,21,24,38)$. The tef region alone serves as a useful tool for isolate identification (8). The IGS regions of the nuclear ribosomal gene shows a high level of sequence variation over parts of its $\approx 3 \mathrm{~kb}$ length and has been used to study intraspecific variation in fungi (1). A phylogenetic species was recognized based on reciprocal monophyly of the group within each gene genealogy and the combined phylogeny of tef and ben $\mathrm{A}$.

The objectives of this study were to (i) determine the phylogenetic relationships among isolates of $F$. avenaceum with respect to origins from lisianthus versus other hosts, as well as geographic origin; (ii) determine if the collection of isolates from lisianthus have descended from an exclusive common ancestor; (iii) generate a database of $F$. avenaceum sequences useful for purposes of taxonomy, management and control; and (iv) determine whether $F$. avenaceum isolates from non-lisianthus hosts were capable of causing crown and stem rot on lisianthus.

\section{MATERIALS AND METHODS}

Collection of isolates. A total of 65 Fusarium isolates were collected for this study. Forty-one isolates were from lisianthus grown in different greenhouses, and 24 isolates from other hosts. Of these, the 37 Fusarium isolates included in the molecular study are listed in Table 1 . Fifteen $F$. avenaceum were from diseased lisianthus plants collected in several different greenhouses in Florida, California, and Connecticut, and 22 other fusaria, including $F$. avenaceum, provided by the Fusarium Research Center (FRC) culture collection to represent the diverse range of plant hosts, besides lisianthus, and diverse locations (Table 1). Each isolate was obtained from a separate plant. Included were isolates that had been previously connected to other morphologically similar Fusarium species, and given two-

TABLE 1 . Isolates analyzed in this study

\begin{tabular}{|c|c|c|c|c|c|c|c|}
\hline \multirow[b]{2}{*}{ Species identification ${ }^{\mathrm{a}}$} & \multirow[b]{2}{*}{ Host/substrate ${ }^{\mathrm{b}}$} & \multirow[b]{2}{*}{ Origin $^{\mathrm{c}}$} & \multirow[b]{2}{*}{ FRC \# $\#^{\mathrm{d}}$} & \multicolumn{3}{|c|}{ GenBank accession numbers } & \multirow[b]{2}{*}{ Pathogenicity ${ }^{\mathrm{e}}$} \\
\hline & & & & tef & $\operatorname{ben} \mathrm{A}$ & IGS & \\
\hline F. avenaceum & Carnation & California & R-0018 & EU357808 & EU357839 & EU357870 & - \\
\hline F. avenaceum & Soil & Australia & R-3050 & EU357811 & EU357842 & EU357873 & - \\
\hline F. avenaceum & Carnation & South Africa & R-4055 & EU357812 & EU357843 & EU357874 & + \\
\hline F. avenaceum & Wheat & Brazil & R-4935 & EU357813 & EU357844 & EU357875 & - \\
\hline F. avenaceum & Soybean & Japan & $\mathrm{R}-6750$ & EU357818 & EU357849 & EU357880 & - \\
\hline F. avenaceum & Common osier & Sweden & $\mathrm{R}-8483$ & EU357819 & EU357850 & EU357881 & + \\
\hline F. avenaceum & Barley & Sweden & R-9092 & EU357820 & EU357851 & EU357882 & + \\
\hline F. avenaceum & Citrus & Iran & R-9369 & EU357821 & EU357852 & EU357883 & - \\
\hline F. avenaceum & Lisianthus & Florida & R-9490 & EU357822 & EU357853 & EU357884 & N/A \\
\hline F. avenaceum & Lisianthus & California & R-9495 & EU357823 & EU357854 & EU357885 & N/A \\
\hline F. avenaceum & Lisianthus & California & R-9496 & EU357824 & EU357855 & EU357886 & N/A \\
\hline F. avenaceum & Lisianthus & Connecticut & R-9801 & EU357830 & EU357861 & EU357891 & + \\
\hline F. avenaceum & Lisianthus & Connecticut & R-9802 & EU357831 & EU357862 & EU357892 & + \\
\hline F. avenaceum & Lisianthus & California & R-9804 & EU357832 & EU357863 & EU357893 & + \\
\hline F. avenaceum & Lisianthus & Connecticut & R-9805 & EU357833 & EU357864 & EU357894 & + \\
\hline F. avenaceum & Lisianthus & Connecticut & R-9806 & EU357834 & EU357865 & EU357895 & + \\
\hline F. avenaceum & Lisianthus & Connecticut & R-9807 & EU357835 & EU357866 & EU357896 & + \\
\hline F. avenaceum & Lisianthus & Connecticut & R-9808 & EU357836 & EU357867 & EU357897 & + \\
\hline F. avenaceum & Lisianthus & Florida & R-9809 & EU357837 & EU357868 & EU357898 & + \\
\hline F. avenaceum & Lisianthus & Florida & R-9810 & EU357838 & EU357869 & & + \\
\hline F. avenaceum & Barley & Finland & R-4954* & EU357814 & EU357845 & EU357876 & - \\
\hline F. avenaceum & Soil & Australia & R-3053 & FJ154734 & FJ154740 & FJ154746 & - \\
\hline F. avenaceum & Potato & Egypt & R-6687 & EU357816 & EU357847 & EU357878 & + \\
\hline F. acuminatum & Lavendula & France & R-9382 & FJ154733 & FJ154739 & FJ154745 & N/A \\
\hline
\end{tabular}

${ }^{a}$ Species identification based on morphology/phylogenetics. Fusarium species, host, origin, and pathogenicity of isolates. Fusarium species used as outgroups are included.

b The host substrate.

c Geographic origin.

${ }^{\mathrm{d}}$ Specimen number in the Fusarium Research Center, Pennsylvania State University, PA. * Alternate isolate designations are in parentheses; R-9528 (NRRL 26949), R-9529 (NRRL 26950), and R-4954 (Gerlach 62156).

e Pathogenicity test denoted by a "-" if not pathogenic, and a "+" if it caused disease on lisianthus. N/A = isolate was not tested. An empty cell for the GenBank number indicates sequence is unavailable. 
name identification designations, such as $F$. avenaceum-acuminatum (R-3049, R-3050, and R-3053) and F. avenaceum-arthrosporioides (R-4954 and R-6687) as they could not be conclusively identified as $F$. avenaceum based solely on morphology.

All isolates were cultured on carnation leaf agar (CLA; $2 \%$ water agar amended with pieces of sterilized carnation leaves) from single-spored germinated macroconidia, lyophilized, and stored at the FRC at $-40^{\circ} \mathrm{C}$. Three typical isolates of $F$. acuminatum (R-2165, R-6934, and R-7408) were used as an outgroup in the analysis.

DNA extraction and polymerase chain reaction. Isolates taken from the culture collection were grown on CLA for $24 \mathrm{~h}$ and several $\approx 10 \mathrm{~mm}^{2}$ plugs of agar containing fresh growth of mycelia were transferred to test tubes containing $10 \mathrm{ml}$ of sterile potato dextrose broth (PDB; Difco Laboratories, Detroit). The test tubes were placed on a shaker $(35 \mathrm{rpm})$ for 4 days at 22 to $24^{\circ} \mathrm{C}$ and mycelia were filtered and frozen in 0.5-ml Eppendorf tubes. The samples were lyophilized for $24 \mathrm{~h}$ before DNA was extracted using DNeasy Plant Minikits (Qiagen, Inc., Valencia, CA).

An approximate 690-bp fragment of the tef gene was amplified using primers ef1 and ef 2 (24) in all isolates, using polymerase chain reaction (PCR) as previously described (9). Also an $\approx 1,100$-bp fragment of benA was amplified using the primer pair bena-T1 and bena-T22 (20). The nuclear ribosomal IGS region was amplified $(\approx 3 \mathrm{~kb})$ with the primers NL11 and CNS1 (1). A QIAquick PCR purification kit (Qiagen, Inc.) was used to purify the PCR products prior to sequencing.

Direct sequencing. Sequencing of the amplification product of the tef gene $(\approx 690 \mathrm{bp})$ was carried out using forward and reverse primers, ef 1 and ef 2 . An $\approx 600$-bp portion of the benA-T1/benaT22 PCR product was sequenced in both directions using the primer pair bena-T1 and bena-T2. Four new internal primers were developed to sequence the IGS rDNA region: AvnIGS1, GATCAGGTACTGAGAGGGAT; AvnIGS2, CGCATCCCTCTCAGTACC; AvnIGS3, CCACCAAACCACARAACC; and AvnIGS4, TTTCCCCAATGATTTCTCT. Sequences were generated using an Applied Biosystems Big Dye Terminator sequencing kit according to manufacturer's recommendations. Sequences were generated on an automated DNA Sequencer (Applied Biosystems 377 or 3730 XL; PE Biosystems, Foster City, CA), at the Penn State Plant Pathology Core Instrumentation facility or Penn State Nucleic Acid Facility.

Phylogenetic analysis. Sequences were edited using Sequencher v.3.1.1. (Gene Codes Corporation, Ann Arbor, MI) and initially aligned using Clustal X Multiple Sequence Alignment Program (v.1.81, Julie Thompson and Francois Jeanmougin) followed by visual adjustment using Se-Al v.2.Oa3 (University of Oxford, Oxford, UK). Gaps in the alignment were considered missing data. Phylogenetic analysis using parsimony (PAUP $4.0 \mathrm{~b} 10)$ was used for generating phylogenetic trees (36). Modeltest version 3.06 (30) was used to determine the nucleotide substitution model best suited to the data set. Phylogenetic and molecular evolutionary analyses using Kimura-2-parameter (K2P) model to generate neighbor-joining, maximum parsimony, and maximum likelihood (ML) trees were also carried out using either PAUP $4.0 \mathrm{~b} 10$ or MEGA version 2.1 (14) on individual and combined data sets for the tef, benA, and IGS gene sequences. For maximum parsimony analysis, the heuristic search option was used with stepwise addition and tree bisection-reconnection branch swapping. Isolates of $F$. acuminatum were designated as outgroup taxa as they lie close to but outside the $F$. avenaceum clade. To test the stability of clades, bootstrap tests were performed with 1,000 replicates in all analyses except in ML, where 500 replicates were performed.

Nucleotide sequence accession numbers. All DNA sequence data generated for this study have been deposited in GenBank under accession nos. EU357808 to EU357898 and FJ154733 to FJ154748. Sequence alignments were submitted to TREEBASE (available online), submission number SN 3780. All tef sequences have been added to the FUSARIUM-ID DNA sequence identification database (available online).

Pathogenicity tests. Pathogenicity tests were conducted in two independent experiments to determine whether isolates from nonlisianthus hosts were capable of causing crown and stem rot of lisianthus (Table 1). Forty-one isolates from lisianthus, as well as 24 isolates from other hosts were tested on lisianthus. Pathogenicity tests were carried out at the Connecticut Agricultural Experimental Station in the spring when seedlings were commercially available. Four-week-old lisianthus seedlings (cultivar Echo Blue) were provided by Ball Seed Company (Chicago, IL) in 384 cell plug trays. Seedlings were transferred to 36 cell plug trays for 3 weeks and inoculated with $F$. avenaceum isolates. Four seedlings per isolate per experiment were inoculated and border cells on both sides of inoculated plants were left untreated. Spore inoculum was produced by growing the cultures on CLA plates for 10 days under cool white light at temperatures of $20^{\circ} \mathrm{C}$ at night and $25^{\circ} \mathrm{C}$ during the day. Spores were washed from the plates with distilled water and spore concentration was adjusted to $10^{6} \mathrm{spores} / \mathrm{ml}$. Twenty milliliters of inoculum was applied to the base of each seedling. Control plants were treated with distilled water. Plants were held at greenhouse temperatures. Set temperatures were $16^{\circ} \mathrm{C}$ for heating and $27^{\circ} \mathrm{C}$ for ventilation. Seedling death was recorded over 3 months. If one or more plants per isolate treatment were symptomatic the result was recorded as a "+" for pathogenicity and as a "-_" if no symptoms were seen in any of the plants inoculated. The pathogen was reisolated from two symptomatic plants per isolate treatment and identified morphologically to confirm recovery of the pathogen.

\section{RESULTS}

Phylogenetic analysis. The lengths of the sequence alignments were 582 and 656 sites, respectively, for the benA and tef regions. Phylogenetic analyses using several nucleotide substitution models applied to the individual tef, benA, and IGS data sets and combined ben $\mathrm{A}$ and tef data set produced a strongly supported (100\% bootstrap support) exclusive group that included all $F$. avenaceum isolates regardless of the method chosen for analysis. Within the $F$. avenaceum clade, isolates from lisianthus were scattered with no evidence of phylogenetic structure with respect to host. Falling outside the clade were two isolates from the FRC incorrectly identified as $F$. avenaceum, R-9382 and R-6678, based on morphology. Because the analyses of both genes, tef and ben $\mathrm{A}$, yielded phylogenetic inferences that were not in significant conflict as assessed by bootstrap support, the data were combined and analyzed using PAUP (Fig. 1). There were a total of 11 twolocus haplotypes in the combined analysis of the two genes. The results of the combined analysis showed similar topology as the two separate data sets with the same set of $F$. avenaceum isolates forming a strongly supported clade, clearly distinct from the $F$. acuminatum outgroup. The lisianthus isolates were scattered within this $F$. avenaceum clade. Analyzed separately in a subset of 33 isolates, the IGS data provided more resolution within the $F$. avenaceum clade than either the ben $\mathrm{A}$ or tef data, and again did not show the lisianthus isolates to be monophyletic or clonal (Fig. 2 ). The IGS data were not combined with the tef and benA analysis as there were fewer isolates sequenced for the IGS locus. There were a total of 19 haplotypes in the IGS analysis compared with 11 two-locus haplotypes in the combined analysis of the tef and benA genes. Representative tef sequences from three $F$. avenaceum isolates were compared to a database of tef sequences from 158 diverse fusaria using BLAST against the FUSARIUMID (8) and GenBank databases. All three sequences were most closely related to a single $F$. avenaceum sequence in the database. It was not possible to compare this clade to a type for $F$. avenaceum as this species is in need of neo-typification and a more 
extensive multilocus phylogenetic analysis. Grouping within the $F$. avenaceum clade, based on all three loci, were isolates previously identified morphologically as $F$. avenaceum-arthrosporioides $(\mathrm{R}-4954=\mathrm{BBA}$ 62155, $\mathrm{R}-6687)$ and as $F$. avenaceumacuminatum (R-3049, R-3050, and R-3053).
Pathogenicity tests. Three months after inoculation, seedlings were rated for the number of symptomatic plants. Once plants began to exhibit symptoms, they died within a week. Isolations from the bright orange sporodochia produced on diseased plants confirmed the recovery of the pathogen. At total of 49 out of 65

Combined tef and benA
ML tree with K2P model
$-\ln L 225.2$
1238 bp

F.avenaceum CA R-9496 Lisianthus

78

F.avenaceum Clade 100

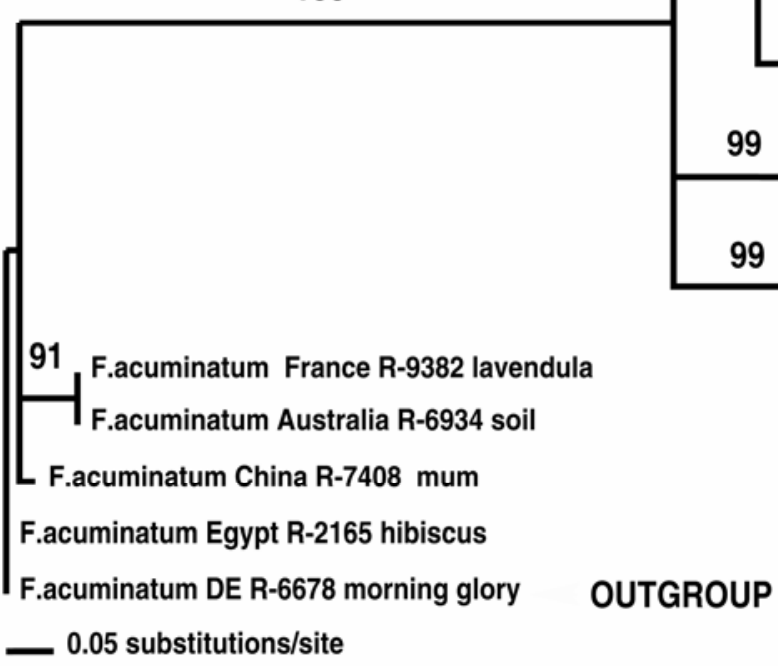

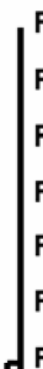

F.avenaceum CA R-18 carnation
F.avenaceum PA R-48 turf

F.avenaceum Australia R-3050 soil

F.avenaceum CA R-6550 carnation

F.avenaceum Columbia R-6747 carnation

F.avenaceum CT R-9801 Lisianthus

F.avenaceum CT R-9802 Lisianthus

F.avenaceum CA R-9804 Lisianthus

F.avenaceum CT R-9805 Lisianthus

F.avenaceum CT R-9806 Lisianthus

F.avenaceum CT R-9807 Lisianthus

F.avenaceum CT R-9808 Lisianthus

F.avenaceum FL R-9809 Lisianthus

F.avenaceum S.Africa R-4055 carnation

F.avenaceum Brazil R-4935 wheat

F.avenaceum CA R-9495 Lisianthus

F.avenaceum ND R-9528 barley

F.avenaceum FL R-9798 Lisianthus

F.avenaceum CT R-9800 Lisianthus

NonPathogenic

Pathogenic

NonPathogenic

Pathogenic

Pathogenic

Pathogenic

Pathogenic

Pathogenic

Pathogenic

Pathogenic

Pathogenic

Pathogenic

Pathogenic

Pathogenic

NonPathogenic

NonPathogenic

Pathogenic

Pathogenic

Pathogenic

NonPathogenic

Pathogenic

Pathogenic

F.avenaceum Sweden R-9092 barley Pathogenic

99 F.avenaceum Germany R-4954 barley NonPathogenic

F.avenaceum Egypt R-6687 potato Pathogenic

99 F.avenaceum Japan R-6750 soybean NonPathogenic

F.avenaceum Iran R-9369 citrus NonPathogenic

99 F.avenaceum Australia R-3049 soil NonPathogenic F.avenaceum Australia R-3053 soil NonPathogenic

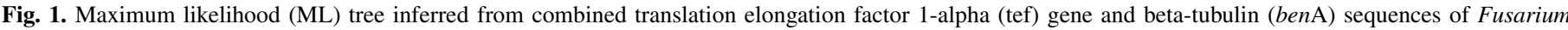

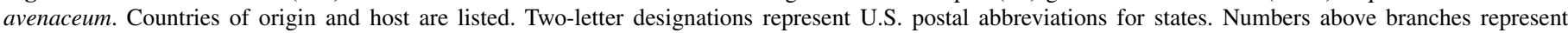
bootstrap values over 75\%. Three lisianthus isolates R-9495, R-9496, and R-9490 were not tested for pathogenicity on lisianthus. 
isolates tested were pathogenic on lisianthus, including isolates of $F$. avenaceum that were originally recovered from other host plants (Table 1). A total of 37 out of 41 isolates from lisianthus were found to be pathogenic, while 12 out of 24 from other hosts caused disease on lisianthus as well. All control plants and border plants were asymptomatic. Results of the two independent pathogenicity tests were similar.

\section{DISCUSSION}

The primary objective of this study was to investigate the phylogenetic relationships among isolates of $F$. avenaceum with respect to origins from lisianthus versus other hosts and geographic origins. Our data clearly indicate that $F$. avenaceum isolates from lisianthus are not phylogenetically separated from $F$.

\section{IGS \\ ML tree with K2P model \\ $-\ln \mathrm{L} 688.4$ \\ 1383 bp}

F.avenaceum CA R-18 carnation

F.avenaceum Brazil R-4935 wheat

F.avenaceum ND R-9528 barley

99

F.avenaceum CA R-9495 Lisianthus

F.avenaceum CA R-9496 Lisianthus

F.avenaceum FL R-9798 Lisianthus

109 F.avenaceum FL R-9490 Lisianthus

F.avenaceum ND R-9529 barley

F.avenaceum Japan R-6750 soybean

98 F.avenaceum CT R-9805 Lisianthus

F.avenaceum CT R-9807 Lisianthus

F.avenaceum CT R-9808 Lisianthus

F.avenaceum PA R-48 turf

F.avenaceum Sweden R-8483 viminales

F.avenaceum CA R-6550 carnation

F.avenaceum CT R-9802 Lisianthus

F.avenaceum FL R-9809 Lisianthus

F.avenaceum Iran R-9369 citrus

F.avenaceum Germany R-4954 barley

F.avenaceum CT R-9797 Lisianthus

F.avenaceum CT R-9801 Lisianthus

F.avenaceum CA R-9804 Lisianthus

F.avenaceum Egypt R-6687 potato

F.avenaceum Columbia R-6747 carnation

F.avenaceum Australia R-3050 soil

100 F.avenaceum S.Africa R-4055 carnation

F.avenaceum Sweden R-9092 barley

100

F.avenaceum Australia R-3049 soil

F.avenaceum Australia R-3053 soil

F.acuminatum China R-7408 mums

F.acuminatum France R-9382 lavendula

F.acuminatum DE R-6678 morning glory

OUTGROUP

Fig. 2. Maximum likelihood (ML) tree inferred from analysis of intergenic spacer (IGS) regions of nuclear ribosomal RNA gene sequences of Fusarium avenaceum. Countries of origin and host are listed. Two-letter designations represent U.S. postal abbreviations for states. Numbers above branches represent bootstrap values over $75 \%$. 
avenaceum isolates from diverse localities and hosts. There was no evidence that isolates from lisianthus formed a distinct group within the $F$. avenaceum clade based on geographic origin or host substrate. Based on this lack of phylogenetic structure, it appears that the ability to cause disease on lisianthus occurs broadly within this species.

The lack of phylogenetic structure observed in the $F$. avenaceum clade with regard to the lisianthus isolates could be the result of inadequate resolution from the molecular markers employed. However, these same markers have demonstrated moderate to high levels of phylogenetic structure in other morphologically defined species of Fusarium, including $F$. oxysporum (24) and $F$. solani (19) species complexes, $F$. graminearum and its relatives $(25,29)$, members of the $F$. lateritium clade (10), F. hostae and $F$. redolens $(3,9)$, and the Gibberella fujikuroi species complex $(22,26)$. It is possible that more highly variable markers such as other DNA sequences and microsatellites may uncover phylogenetic structure not evident in the tef, benA, and IGS gene trees.

Using GCPSR to investigate species boundaries in this study has shown that $F$. avenaceum is a phylogenetically distinct species based on reciprocal monophyly within three gene genealogies. The individual and combined tef and benA, and IGS trees indicated one strongly supported clade (100\% bootstrap support) common to all three gene genealogies separating the $F$. avenaceum group from the $F$. acuminatum outgroup species. Within each group, the gene genealogies were not significantly in conflict. Our results indicate that most isolates previously identified morphologically as $F$. avenaceum share enough synapomorphic characters in the ben A, tef sequences, and IGS region to allow reliable molecular identification. Simple single nucleotide polymorphism (SNP) based methods can be developed from these synapomorphic sites to allow rapid and accurate identification (27) of the species.

Gerlach and Nirenberg (11) and Nelson et al. (18) both applied similar morphological species concepts to $F$. avenaceum. Isolates analyzed in this study were first identified morphologically using the criteria described in Nelson et al. (18). This correlation between the morphological and phylogenetic species concepts differs from some Fusarium morphospecies that have broad host ranges, including $F$. solani, $F$. oxysporum, and $F$. subglutinans, where a morphospecies corresponds to multiple phylogenetic species (32). Two isolates, R-9382 and R-6678, were apparently misidentified morphologically as $F$. avenaceum, consistently grouping with the $F$. acuminatum outgroup isolates for all three loci sequenced and will henceforth be referred to as $F$. acuminatum. $F$. avenaceum-acuminatum isolates R-3049 and R-3053 from Australian soil formed a unique basal subclade within the main clade of $F$. avenaceum isolates for all three gene regions, but did not group with the $F$. acuminatum outgroup. They were initially identified ambiguously as $F$. avenaceum-acuminatum based on morphological similarities and were listed with the $F$. avenaceum in the FRC database. Their phylogenetic uniqueness coupled with the ambiguity attached to their morphological identification suggests that they may represent an undescribed species. They were also nonpathogenic on lisianthus. The phylogenetic status of these two isolates deserves further study. Another pair of isolates previously identified as $F$. avenaceum, R-6750 from soybean (Japan) and R-9369 from citrus (Iran), were distinct basal members of the $F$. avenaceum clade in the combined tef and ben $\mathrm{A}$ analysis, as were the two isolates previously identified as $F$. avenaceum-arthrosporioides, R-4954 from barley (Germany) and R-6687 from potato (Egypt). However, R-4954 was nonpathogenic while R-6687 was pathogenic on lisianthus. These four isolates did not appear in the same or basal clade in the IGS analysis. Further phylogenetic analyses among these six basal taxa will be required to determine species boundaries and if these are cryptic species. Additional genes such as $R P B 2$, which has been used to look at nucleotide variation within the species level in Fusarium (27), can be used to clarify the limits of species nested within the main $F$. avenaceum clade. $F$. acuminatum and $F$. arthrosporioides are distinct from $F$. avenaceum morphologically but appear closely related based on analyses of the tef locus across a wide spectrum of fusaria (unpublished data). In a molecular analysis of $F$. arthrosporioides and $F$. avenaceum isolates from Europe, Yli-Mattila et al. (39) found that F. arthrosporioides isolates clustered within the European $F$. avenaceum group. They suggest that it may be necessary to place the European $F$. arthrosporioides strains in the same species with their European and American $F$. avenaceum as they did not find clear molecular characters specific to $F$. avenaceum or $F$. arthrosporioides (39).

Because of the lack of quantitative data and due to sampling bias involved in the collection of isolates from diseased plant hosts, statistical analysis of the pathogenicity data was not attempted and no quantitative conclusions were made about pathogenicity. However, the lack of phylogenetic structure associated with isolates from diseased lisianthus, and the fact that many of the isolates from other hosts were capable of causing disease on lisianthus, suggests that any isolate of $F$. avenaceum may potentially be pathogenic on lisianthus. Therefore, the development of resistant cultivars should consider the diversity of $F$. avenaceum isolates, not only those obtained from lisianthus. Most importantly, control methods would have to take into account the possible spread of $F$. avenaceum from other hosts in the same locality, whether in a large-scale production facility producing potted or field-grown ornamentals or other hosts of $F$. avenaceum that could become a source of inoculum. Although isolates previously identified as $F$. avenaceum fall into this strongly supported phylogenetic group, it is possible that $F$. avenaceum isolates may form a species complex including $F$. arthrosporioides and other cryptic taxa. However, the degree of phylogenetic diversity in $F$. avenaceum appears to be much lower than that observed in many other morphological species of Fusarium (40). This phylogenetic analysis, where a number of $F$. avenaceum isolates from many different geographic areas and many different host substrates has been used, will benefit further studies and neo-typing of the species based on future research. The multilocus database of sequences developed in this study is now available (17), providing an important molecular and morphological framework for additional phylogenetic studies of these Fusarium species causing disease on ornamentals and other plant hosts worldwide.

\section{ACKNOWLEDGMENTS}

We thank J. Juba, T. Seijo, and E. O'Dowd for technical assistance and $\mathrm{N}$. Zhang for assistance with the maximum likelihood analyses. We also thank the two anonymous reviewers for valuable comments on the manuscript. The American Floral Endowment provided partial funding for this study.

\section{LITERATURE CITED}

1. Aoki, T., O’Donnell, K., Homma, Y., and Lattanzi, A. R. 2003. Suddendeath syndrome of soybean is caused by two morphologically and phylogenetically distinct species within the Fusarium solani species complex $-F$. virguliforme in North America and F. tucumaniae in South America. Mycologia 95:660-684.

2. Baayen, R. P., O’Donnell, K., Bonants, P. J. M., Cigelnik, E., Kroon, L. P. N. M., Roebroeck, E. J. A., and Waalwijk, C. 2000. Gene genealogies and AFLP analyses in the Fusarium oxysporum complex identify monophyletic and nonmonophyletic formae speciales causing wilt and rot disease. Phytopathology 90:891-900.

3. Baayen, R. P., O’Donnell, K., Breeuwsma, S., Geiser, D. M., and Waalwijk, C. 2001. Molecular relationships of fungi within the Fusarium redolens-F. hostae clade. Phytopathology 91:1037-1044.

4. Booth, C. 1971. The Genus Fusarium. Commonwealth Mycological Institute, Kew, UK.

5. Cook, R. J. 1967. Gibberella avenacea sp. n., perfect stage of Fusarium roseum f. sp. cerealis “Avenaceum”. Phytopathology 57:732-736. 
6. Cook, R. J. 1968. Fusarium root and foot rot of cereals in the Pacific Northwest. Phytopathology 58:127-131.

7. Elmer, W. H., and McGovern, R. J. 1997. Vegetative compatibility among isolates of Fusarium avenaceum from lisianthus. (Abstr.) Phytopathology 87(suppl.):S28.

8. Geiser, D. M., Jimenez-Gasco, M., Kang, S., Makalowska, I., Veeraraghavan, N., Ward, T. J., Zhang, N., Kuldau, G. A., and O'Donnell, K. 2004. Fusarium-ID v.1.0: A DNA sequence database for identifying Fusarium. Eur. J. Plant Pathol. 110:473-479.

9. Geiser, D. M., Juba, J. H., Wang, B., and Jeffers, S. N. 2001. Fusarium hostae sp. nov., a relative of $F$. redolens with a Gibberella teleomorph. Mycologia 93:670-678.

10. Geiser, D. M., Lewis, I. M. L., Hakiza, G., Juba, J. H., and Miller, S. A. 2005. Gibberella xylarioides (anamorph: Fusarium xylarioides), a causative agent of coffee wilt disease in Africa, is a previously unrecognized member of the G. fujikuroi species complex. Mycologia 97:191-201.

11. Gerlach, W., and Nirenberg, H. 1982. The genus Fusarium-A pictorial atlas. Mitt. Biol. Bundesanst. Land-Forstwirtsch. Berlin-Dahlem. 209:1406.

12. Gordon, T. R., and Martyn, R. D. 1997. The evolutionary biology of Fusarium oxysporum. Annu. Rev. Phytopathol. 35:111-128.

13. Knauss, J. F. 1975. Description and control of Fusarium tuber rot of Caladium. Plant Dis. Rep. 59:975-979.

14. Kumar, S., Tamura, K., Jakobsen, I. B., and Nei, M. 2001. MEGA2: Molecular Evolutionary Genetics Analysis Software. Arizona State University, Temple, AZ.

15. McGovern, R. J., and Harbaugh, B. K. 1997. Finding fungicides for Fusarium. Greenhouse Grower 15:40-45.

16. McGovern, R. J., Harbaugh, B. K., and Polston, J. E. 1997. Severe outbreaks of crown and stem rot of lisianthus in Florida. Phytopathology 87:S64.

17. Nalim, F. A., McGovern, R. J., Elmer, W. H., and Geiser, D. M. 2002. New clades of the Fusarium solani species complex associated with tuber rot of caladium. Inoculum 53:46.

18. Nelson, P. E., Tousson, T. A., and Marasas, W. F. O. 1983. Fusarium Species; An Illustrated Manual for Identification. Pennsylvania State University Press, PA.

19. O'Donnell, K. 2000. Molecular phylogeny of the Nectria haematococcaFusarium solani species complex. Mycologia 92:919-938.

20. O'Donnell, K., and Cigelnik, E. 1997. Two divergent intragenomic rDNA ITS2 types within a monophyletic lineage of the fungus Fusarium are nonorthologous. Mol. Phylogenet. Evol. 7:103-116.

21. O'Donnell, K., Cigelnik, E., and Casper, H. H. 1998. Molecular phylogenetic, morphological, and mycotoxin data support reidentification of the Quorn mycoprotein fungus as Fusarium venenatum. Fungal Genet. Biol. 23:57-67.

22. O’Donnell, K., Cigelnik, E., and Nirenberg, H. I. 1998. Molecular systematics and phylogeography of the Gibberella fujikuroi species complex. Mycologia 90:465-493.

23. O'Donnell, K., and Gray, L. E. 1995. Phylogenetic relationships of the soybean sudden-death syndrome pathogen Fusarium solani f. sp. phaseoli inferred from rDNA sequence data and PCR primers for its identification. Mol. Plant-Microbe Interact. 8:709-716.

24. O’Donnell, K., Kistler, H. C., Cigelnik, E., and Ploetz, R. C. 1998. Multiple evolutionary origins of the fungus causing Panama disease of banana: Concordant evidence from nuclear and mitochondrial gene genealogies. Proc. Natl. Acad. Sci. USA 95:2044-2049.
25. O’Donnell, K., Kistler, H. C., Tacke, B. K., and Casper, H. H. 2000. Gene genealogies reveal global phylogeographic structure and reproductive isolation among lineages of Fusarium graminearum, the fungus causing wheat scab. Proc. Natl. Acad. Sci. USA 97:7905-7910.

26. O’Donnell, K., Nirenberg, H. I., Aoki, T., and Cigelnik, E. 2000. A multigene phylogeny of the Gibberella fujikuroi species complex: Detection of additional phylogenetically distinct species. Mycoscience 41:61-78.

27. O’Donnell, K., Sarver, B. A. J., Brandt, M., Chang, D. C., Noble-Wang, J., Park, B. J., Sutton, D. A., Benjamin, L., Lindsley, M., Padhye, A., Geiser, D. M., and Ward, T. J. 2007. Phylogenetic diversity and microsphere array-based genotyping of human pathogenic fusaria, including isolates from the multistate contact lens-associated U.S. keratitis outbreaks of 2005 and 2006. J. Clin. Microbiol. 45:2235-2248.

28. O’Donnell, K., Sutton, D. A., Rinaldi, M. G., Magnon, K. C., Cox, P. A., Revankar, S. G., Sanche, S., Geiser, D. M., Juba, J. H., van Burik, J.-A. H., Walsh, T. J., Francesconi, A., Anaissie, E. J., Padhye, A., and Robinson, J. S. 2004. Genetic diversity of human pathogenic members of the Fusarium oxysporum complex inferred from gene genealogies and AFLP analyses: Evidence for the recent dispersion of a geographically widespread clonal lineage and nosocomial origin. J. Clin. Microbiol. 42:5109-5120.

29. O’Donnell, K., Ward, T. J., Geiser, D. M., Kistler, C. H., and Aoki, T. 2004. Genealogical concordance between the mating type locus and seven other nuclear genes supports formal recognition of nine phylogenetically distinct species within the Fusarium graminearum clade. Fungal Genet. Biol. 41:600-623.

30. Posada, D., and Crandall, K. A. 1998. Modeltest: Testing the model of DNA substitution. Bioinformatics 14:817-818.

31. Raabe, R. D. 1985. Fusarium wilt of Eustoma grandiflora. Phytopathology 75:1306.

32. Skovgaard, K., Nirenberg, H. I., O’Donnell, K., and Rosendahl, S. 2001. Evolution of Fusarium oxysporum f. sp. vasinfectum races inferred from multigene genealogies. Phytopathology 91:1231-1237.

33. Snyder, W. C., and Hansen, H. N. 1940. The species concept in Fusarium. Am. J. Bot. 27:64-67.

34. Snyder, W. C., and Hansen, H. N. 1941. The species concept in Fusarium with reference to section Martiella. Am. J. Bot. 28:738-742

35. Snyder, W. C., and Hansen, H. N. 1945. The species concept in Fusarium with reference to Discolor and other sections. Am. J. Bot. 32:657-666.

36. Swofford, D. L. 2001. PAUP*. Phylogenetic Analysis Using Parsimony (*and Other Methods). Version 4 ed. Sinauer Associates, Sunderland, MA.

37. Taylor, J. W., Jacobson, D. J., Kroken, S., Kasuga, T., Geiser, D. M., Hibbett, D. S., and Fisher, C. M. 2000. Phylogenetic species recognition and species concepts in fungi. Fungal Genet. Biol. 31:21-32.

38. Yan, K. Y., and Dickman, M. B. 1996. Isolation of a beta-tubulin gene from Fusarium moniliforme that confers cold-sensitive benomyl resistance. Appl. Environ. Microbiol. 62:3053-3056.

39. Yli-Mattila, T., Paavanen-Huhtala, S., Bulat, A. A., Alekhina, I. A., and Nirenberg, H. I. 2002. Molecular, morphological, and phylogenetic analysis of the Fusarium avenaceum/F. arthrosporioides $/ F$. tricinctum species complex-a polyphasic approach. Mycol. Res. 106:655-669.

40. Zhang, N., O’Donnell, K., Sutton, D. A., Nalim, F. A., Summerbell, R. C., Padhye, A., and Geiser, D. M. 2006. Members of the Fusarium solani species complex that cause infections in both humans and plants are common in the environment. J. Clin. Microbiol. 44:2186-2190. 